NURSING FOCUS

\title{
Nurse prescribing for contraceptive care and sexual health
}

\author{
Pam Campbell, MSc, RGN, Principal Lecturer, Primary Care Nursing, Staffordshire University, Stafford, UK
}

Correspondence: Mrs Pam Campbell, Primary Care Nursing, Staffordshire University, Blackheath Lane, Stafford, StaffordshireST18 0AD, UK.E-mail:p.k.campbell@staffs.ac.uk

(Accepted 15 July 2004)

Journal of Family Planning and Reproductive Health Care 2004; 30(4): 255-256

Background

The Royal College of Nursing first proposed that nurses should be able to prescribe the combined pill in 1975. It has taken almost 30 years for this idea to become reality. The authority to prescribe represents much more than the right to sign for a plan of treatment or care. It also signifies an ability to assess, diagnose and evaluate. The advent of nurse prescribing is therefore a significant milestone in nursing history. Nurses working in family planning clinics (FPCs) who opt to become prescribers will be liberated to initiate all types of contraception - from combined oral contraceptive pills, progestogen-only pills, injectables to intrauterine devices/systems - from the Nurse Prescribers' Extended Formulary. ${ }^{1}$

\section{Patient Group Directions}

Many nurses working in FPCs issue or administer treatment using Patient Group Directions ${ }^{2}$ (PGDs). This is not prescribing; the legal accountability is entirely different. PGDs allow nurses to provide treatment after following a rigid flowchart, which ensures that the patient is eligible for a specified treatment. The employing organisation will indemnify nurses using PGDs and individual accountability or choice is negligible. Although the use of PGDs accelerates treatment in many instances, it also perpetuates a practice of encouraging nurses to simply follow instructions.

Varying formats of nurse prescribing

Prescribing, in contrast, requires the interpretation of a clinical picture and the analysis of symptoms. This provides a wide range of options from which the patient and professional can select the most appropriate treatment.

Any registered nurse, working within the National Health Service (NHS), can now apply to become an extended independent/supplementary nurse prescriber. ${ }^{3}$ In order to be accepted on a prescribing course, nurses are required to demonstrate that gaining prescriptive authority will directly benefit patient care within their area of clinical practice. They also need to demonstrate that they are capable of studying at degree level.

\section{Limited formulary prescribing}

This type of prescribing (sometimes referred to as V100 prescribing because of the code used to record this on the Nursing and Midwifery Council register) relates only to health visitors and district nurses who gain prescribing rights whilst undertaking their post-registration degree in specialist practice. They are entitled to prescribe from a very limited range of medicines (that do not include contraceptive pills or injectables) and wound care products, together with all 'P' category drugs, and all General Sales List drugs. This type of prescribing has been in existence since 1998.

Extended independent nurse prescribing

Extended independent nurse prescribing was introduced in April 2002. This enables any nurse who has successfully completed a recognised and professionally approved training course to prescribe from a rapidly increasing range of prescription-only medicines (currently almost 200 drugs). The full range of these drugs is available to view on the Department of Health website. ${ }^{4}$ In addition, from April 2003 , nurses undertaking this prescribing course also gain qualification as a supplementary prescriber.

\section{Supplementary prescribing}

Supplementary prescribing is a new legal category of prescribing. The supplementary prescriber is able to prescribe any drug (with the exception of controlled drugs) listed within a patient-specific clinical management plan. An independent prescriber (usually a doctor) and a supplementary prescriber work together to draw up a clinical management plan for a specific patient with a defined chronic condition. The plan covers a defined time span (usually around 1 year) and can include any drug (apart from controlled drugs) that may potentially be needed in connection with the chronic condition. Pharmacists can also apply to become supplementary prescribers, and it is envisaged that by early 2005 several other health professionals (such as physiotherapists) will be able to become supplementary prescribers if they undertake an appropriate training course.

Nurses working in family planning are more likely to prescribe independently as the formulary is so well suited to their needs. However, nurses working with patients who have $\mathrm{HIV}$, for example, would find supplementary prescribing more useful in dealing with this long-term condition.

\section{Content of the nurse prescribing course}

The education programme for nurse prescribing comprises 26 days over a 3- or 6-month period, ${ }^{5}$ plus 12 days (or 72 hours) tuition in practice from a clinical mentor, who must be at a minimum of specialist registrar level. The classroom-based education can only deal with generic principles relating to prescribing and pharmacology because of the diverse mix of students. The responsibility for learning relating to applied therapeutics in specialist areas therefore rests with the clinical mentor. Although the time commitment and responsibility can appear daunting for many busy doctors, it also represents an opportunity to refresh and extend their own knowledge base. Anecdotal evidence suggests that doctors who act as designated mentors for nurses undertaking prescribing courses generally enjoy the experience. They also gain insight into nurses' capabilities and this can highlight the way forward for service redesign. Nurses who are experienced within family planning will often know, from experience, which particular type of contraceptive preparation to recommend. However, they need to be challenged as to why they are recommending one treatment rather than another. This will raise confidence in their decisionmaking abilities. Initially they may find this particularly difficult with differing preparations of contraceptive pills. However, the role of the doctor designated as prescribing mentor is to help nurses determine the evidence base underlying their decisions and ensure they have a strong rationale for recommending treatment.

\section{Using the new skills}

The inevitable question that arises, now that nurses are able to prescribe a wide range of treatment within family planning, is: "Why are doctor-led clinics for family 
planning still assumed to be necessary?' If more nurses trained in family planning were to become nurse prescribers then the current role of doctors in this arena innovative areas. Doctors could become consultants to nurse prescribers. Instead of doctors having to attend clinics they could simply be on call for advice over the telephone. Alternatively, more FPCs could expand their services, as recommended in the National Strategy for Sexual Health and HIV, ${ }^{6}$ with doctors seeing patients who present with complex symptoms or health-related problems whilst nurses provide the contraceptive care. This could be achieved with minimal increase in staffing numbers if more of the existing experienced nurses were to become prescribers. Use of non-professionally trained staff (health care assistants) could be employed to undertake basic tasks such as assistance with and preparation for procedures, and sterilising of instruments. These less highly qualified staff could also undertake administrative duties such as booking such as blood pressure checks, etc.

The current practice of nurses working alongside doctors in many FPCs frequently incurs expensive duplication of effort. The patient consults the nurse, who may simply recommend continuation of treatment, or who may refer on to the doctor for further advice and guidance. This referral on to the doctor frequently occurs because of Trust policies that prevent nurses from changing treatment or initiating new treatments. In effect this system disempowers nurses. It stops them from thinking about the solution to problems and encourages over-reliance on doctors. In order to reverse this trend and use nurses more effectively doctors need to question the reason for every referral. Nurses need to change their way of thinking, so that they consider what they would do if they were the prescriber and if a doctor was unavailable. This is about nurses learning to think in a different way. They will soon could look very different, as it already does in some appointments and undertake routine screening procedures

realise that doctors are not blessed with inspiration for correct treatment, and that diagnosis is not mystical, but that accurate assessment and treatment is dependent on the use of robust evidence and logic.

Changing the behaviour of doctors and nurses will not be instant and will not be without anxieties. Staying within the comfort zone is always an easier option. However, limited resources within the NHS mean that all health professionals have a duty to work in ways that allow full utilisation of their skills. Nurse prescribing has provided nurses in family planning with the tools to do a different and more effective job. If those tools are not used organisations should be called to account.

\section{Statements on funding and competing interests}

Funding. None identified.

Competing interests. None identified.

References

1 Nurse Prescribers' Extended Formulary, 2003-2005. London, UK British Medical Association and the Royal Pharmaceutical Society of Great Britain with the Community Practitioners and Health Visitors Association and the Royal College of Nursing, 2003.

2 National Health Service (NHS) Executive. Patient Group Directions. Health Services Circular HSC 2000/026. London, UK: Department of Health, 2000. [NB. Applicable to England only. Similar regulations are available for Scotland, Wales and Northern Ireland.]

3 Department of Health. Extended Independent Nurse Prescribing Within the NHS: A Guide for Implementation (2nd edn). London, UK Department of Health, February 2004.

4 http://www.dh.gov.uk/assetRoot/04/08/38/85/04083885.pdf.

5 Nursing and Midwifery Council. The Council's Requirements for Extended and Independent Nurse Prescribing and Supplementary Prescribing. London, UK: Nursing and Midwifery Council, 2004.

6 Department of Health. National Strategy for Sexual Health and HIV. London, UK: Department of Health, 2001.

Editor's Note

This is the second in a series of articles looking at aspects of nursing in sexual and reproductive health. An article in the January 2005 issue of the Journal will cover developing the role of the specialist nurse in contraception and sexual health services.

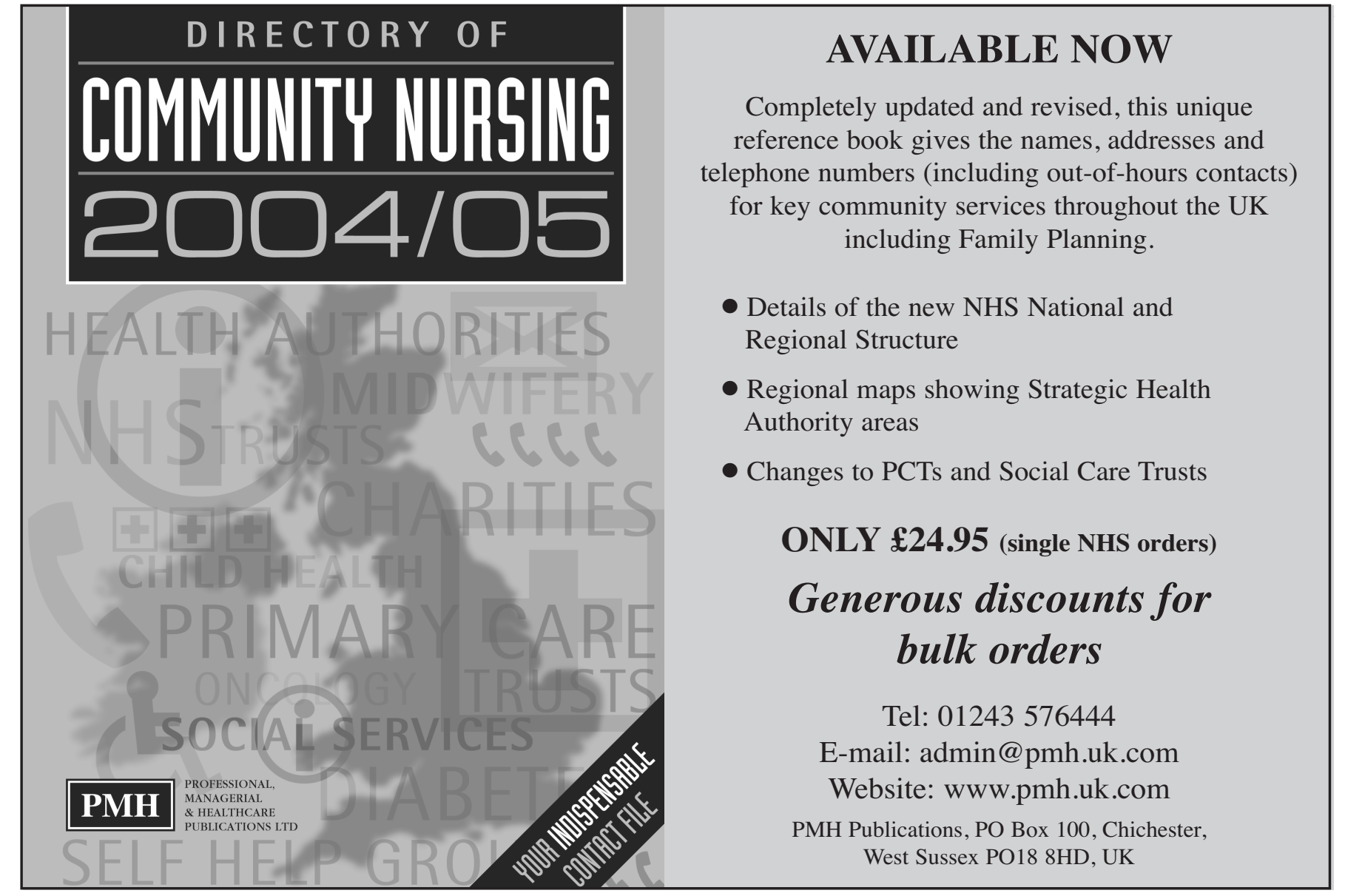

